\title{
Heme Oxygenase: A Font of Multiple Messengers
}

\author{
Solomon H. Snyder, M.D., and David E. Barañano
}

Neurotransmitters and related messenger molecules abound in the brain with numbers ranging between 50 and 100 depending on who is doing the counting. Their chemical structures vary from peptides and large proteins to metal ions such as zinc and the diatomic gases nitric oxide (NO) and carbon monoxide (CO). Most are formed by enzymatic processing although there are notable exceptions. The neurotransmitter pool of zinc comes from a zinc transporter that concentrates the metal into synaptic vesicles together with glutamate. Neurotransmitter pools of amino acids are probably sequestered largely by transporters although this is not altogether clear. For the most part, neurotransmitter peptides are not generated by selective enzymes but by generalized peptide-processing enzyme systems. Highly selective neurotransmitter forming enzymes exist for the biogenic amines; for D-serine, which is formed by serine racemase that converts L-serine to D-serine (Wolosker et al. 1999, 2000); for NO, generated from arginine by NO synthase (NOS); and for $\mathrm{CO}$, formed from heme by heme oxygenase $(\mathrm{HO})$. In most cases the biosynthetic enzyme or series of enzymes yield a single end product. For instance, tryptophan hydroxylase coupled with aromatic amino acid decarboxylase is solely concerned with forming serotonin, while tyrosine hydroxylase, aromatic amino acid decarboxylase, and dopamine betahydroxylase together generate norepinephrine. The focus of this essay is a notable exception. Heme oxygenase gives rise to three discrete products, $\mathrm{CO}$, ferrous iron and biliverdin-bilirubin. Only recently has there

From the The Johns Hopkins University, School of Medicine, Departments of Neuroscience, Pharmacology and Molecular Sciences, and Psychiatry, Baltimore, Maryland.

Address correspondence to: Solomon H. Snyder, The Johns Hopkins University, School of Medicine, Departments of Neuroscience, Pharmacology and Molecular Sciences, and Psychiatry, $725 \mathrm{~N}$. Wolfe Street, Baltimore, MD 21205, USA. Tel.: 410-955-3024; fax: 410-955-3623. E-mail: ssnyder@jhmi.edu

Received November 27, 2000; accepted January 12, 2000. been an appreciation that all three of these products have important physiologic roles which may be complementary.

\section{CARBON MONOXIDE}

$\mathrm{HO}$ was first identified as an enzyme that degrades heme in aging red blood cells. The enzyme was highly concentrated in the spleen, the graveyard of erythrocytes. It is induced by heme, enabling it to respond to hemolysis or tissue destruction, which releases heme from mitochondrial enzymes. Maines and associates (Maines et al. 1986; Trakshel et al. 1986) identified a second enzyme, which is not inducible and is most highly concentrated in the brain and testes. The non-inducible enzyme is designated $\mathrm{HO} 2$, while the inducible form is $\mathrm{HO}$.

Following the identification of NO as a neurotransmitter, we wondered whether there might exist other gaseous transmitter molecules and explored $\mathrm{CO}$ as a possibility. If $\mathrm{CO}$ were a transmitter, a form of $\mathrm{HO}$, presumably $\mathrm{HO} 2$, should be localized to neurons. In situ hybridization reveals $\mathrm{HO} 2$ in discrete neuronal populations in the brain with localizations closely resembling those of soluble guanylyl cyclase (Verma et al. 1993). $\mathrm{CO}$ as well as NO can bind to and activate guanylyl cyclase, which is presumably their second messenger. $\mathrm{HO} 2$ localizations in the brain resemble soluble guanylyl cyclase better than the localizations of NO synthase. In olfactory neuronal cultures inhibition of $\mathrm{HO} 2$ depletes cyclic GMP levels while inhibition of NO synthase is without effect (Verma et al. 1993; Ingi and Ronnett 1995; Ingi et al. 1996).

Direct evidence for $\mathrm{CO}$ as a neurotransmitter came from studies of intestinal non-adrenergic, non-cholinergic transmission (NANC), which accounts for the relaxing phase of peristalsis (Zakhary et al. 1997). Various molecules, including ATP and vasoactive intestinal polypeptide, had been suggested as NANC neurotrans- 
mitters, but there was no definitive evidence. Immunohistochemical staining reveals $\mathrm{HO} 2$ and nNOS often localized to the same myenteric plexus neurons. Mice with targeted deletion of $\mathrm{HO} 2\left(\mathrm{HO}^{-/-}\right)$display about a $50 \%$ reduction in NANC transmission with a similar reduction in $\mathrm{nNOS}^{-/-}$intestine (Zakhary et al. 1997). NANC transmission is virtually abolished in mice with combined deletion of nNOS and HO2 (Zakhary et al. 1997).

CO may also have a transmitter role in the vas deferens where it is localized to neuronal populations that regulate ejaculation (Burnett et al. 1998). Ejaculatory reflexes mediated by the bulbospongiosus muscle are abolished in $\mathrm{HO}^{-/-}$mice, and ejaculation is markedly diminished in intact $\mathrm{HO}^{-/-}$mice. By contrast with the colocalization of the nNOS in the gut, these enzymes have different localizations and functions in the male reproductive track. nNOS is not evident in vas deferens neurons but instead is localized to the penile innervation which does not possess $\mathrm{HO} 2$. NO appears to be the neurotransmitter subserving penile erection. Erection, elicited in rats by stimulation of the cavernous nerves, is markedly reduced by treatment with NOS inhibitors (Burnett et al. 1992).

$\mathrm{HO} 2$ is also important in blood vessel function. Immunohistochemical studies reveal HO2 localized to endothelial layers of blood vessels, analogous to endothelial NOS (Zakhary et al. 1996). In some blood vessels NO is the sole endothelial-derived relaxing factor. However, in many blood vessels relaxation is only partially antagonized by inhibitors of NOS. HO inhibitors reverse the NO-independent relaxation (Zakhary et al. 1996). Thus, in blood vessels, as in the intestinal myenteric plexus, $\mathrm{CO}$ and $\mathrm{NO}$ appear to work synergistically.

How is $\mathrm{HO} 2$ regulated? $\mathrm{CO}$, like NO, cannot be stored in synaptic vesicles so that it must presumably be formed upon demand. In the case of NO, this involves exquisitely fine tuning of nNOS. Glutamate, acting through NMDA receptors, very rapidly activates the formation of $\mathrm{NO}$ in the following way. Calcium, entering cells through NMDA receptor channels, binds to calmodulin which stimulates nNOS (Bredt and Snyder 1990). Might there be a comparably rapid activation of $\mathrm{HO} 2$ ? We found that protein kinase $\mathrm{C}$ phosphorylates $\mathrm{HO} 2$ and augments its catalytic activity (Doré et al. 1999a). Phorbol esters, which activate protein kinase C, stimulate $\mathrm{HO} 2$ activity and bilirubin staining in neuronal cultures. This appears to take place on a very rapid time scale. Hence, calcium entry into cells following neuronal activation might be expected to activate protein kinase $\mathrm{C}$ and thereby $\mathrm{HO} 2$.

How does $\mathrm{CO}$ act as a transmitter? Thus far, its only known target is soluble guanylyl cyclase. Like NO, CO binds to heme in the active site of the enzyme altering its conformation and leading to enzymatic activation. $\mathrm{NO}$ is up to 100 times more potent than $\mathrm{CO}$ in stimulating soluble guanylyl cyclase, so much so that some workers have questioned whether the enzyme is a physiologic target of CO. However, Friebe et al. (1996) have established that treatment of preparations with the drug YC1, which binds to guanylyl cyclase, increases the potency of $\mathrm{CO}$ up to 100-fold. Perhaps in intact tissues comparable conformational alterations of guanylyl cyclase render it sensitive to $\mathrm{CO}$. The finding that intestinal cyclic GMP levels are markedly reduced in $\mathrm{HO}_{2}^{-/-}$mice establishes persuasively that $\mathrm{CO}$ regulates cyclic GMP levels in intact organisms.

\section{BILIRUBIN}

Biliverdin is the direct product of $\mathrm{HO}$ activity. The enzyme biliverdin reductase occurs in almost all tissues of the body in great abundance so that biliverdin levels themselves rarely accumulate. Instead, biliverdin is almost immediately reduced to bilirubin (Figure 1). Bilirubin has long been regarded as a toxic end product of heme metabolism, which is rapidly conjugated to glucuronic acid for urinary excretion. The immaturity of the conjugating system in newborns leads to "physiologic" jaundice, while a substantial minority of human infants develop high enough levels of bilirubin that brain damage from kernicterus is a notable risk.

The brain lacks conjugating enzymes so that bilirubin presumably accumulates from HO activity in neurons. We wondered whether it might have a physiologic role. Ames and collaborators (Stocker et al. 1987a, 1987b) noted that bilirubin is an antioxidant. We explored possible antioxidant-neuroprotectant effects of bilirubin in cerebral cortical cultures of embryonic rats (Doré et al. 1999a). We elicited oxidative damage with hydrogen peroxide. Protoporphorin derivatives that are inhibitors of $\mathrm{HO}$ worsen neurotoxicity. Neurotoxicity is also greatly accentuated in cultures made from $\mathrm{HO}_{2}{ }^{-1-}$ mice. Bilirubin added to the cultures is markedly neuroprotective. Surprisingly, as little as $10 \mathrm{nM}$ bilirubin concentration protects against 10,000 times higher concentrations of hydrogen peroxide. This apparent paradox can be explained by an oxidative-reductive cycling between biliverdin and bilirubin (Figure 1). When bilirubin acts as an antioxidant, it is itself oxidized to biliverdin, which is in turn immediately reduced back to bilirubin by the tissue excess of biliverdin reductase. We have been able to directly demonstrate this process utilizing mixtures of the key chemicals and enzymes (S.H.S. and D.E.B., unpublished observation.)

Compelling evidence that bilirubin is a physiologic neuroprotectant emerges from studies of protein kinase $C$ regulation and neuroprotection by phorbol ester. It is well known that low concentrations of phorbol esters, such as phorbol myristyl acetate (PMA), augment protein kinase $C$, while higher concentrations down-regulate enzyme expression. In hippocampal and cortical 


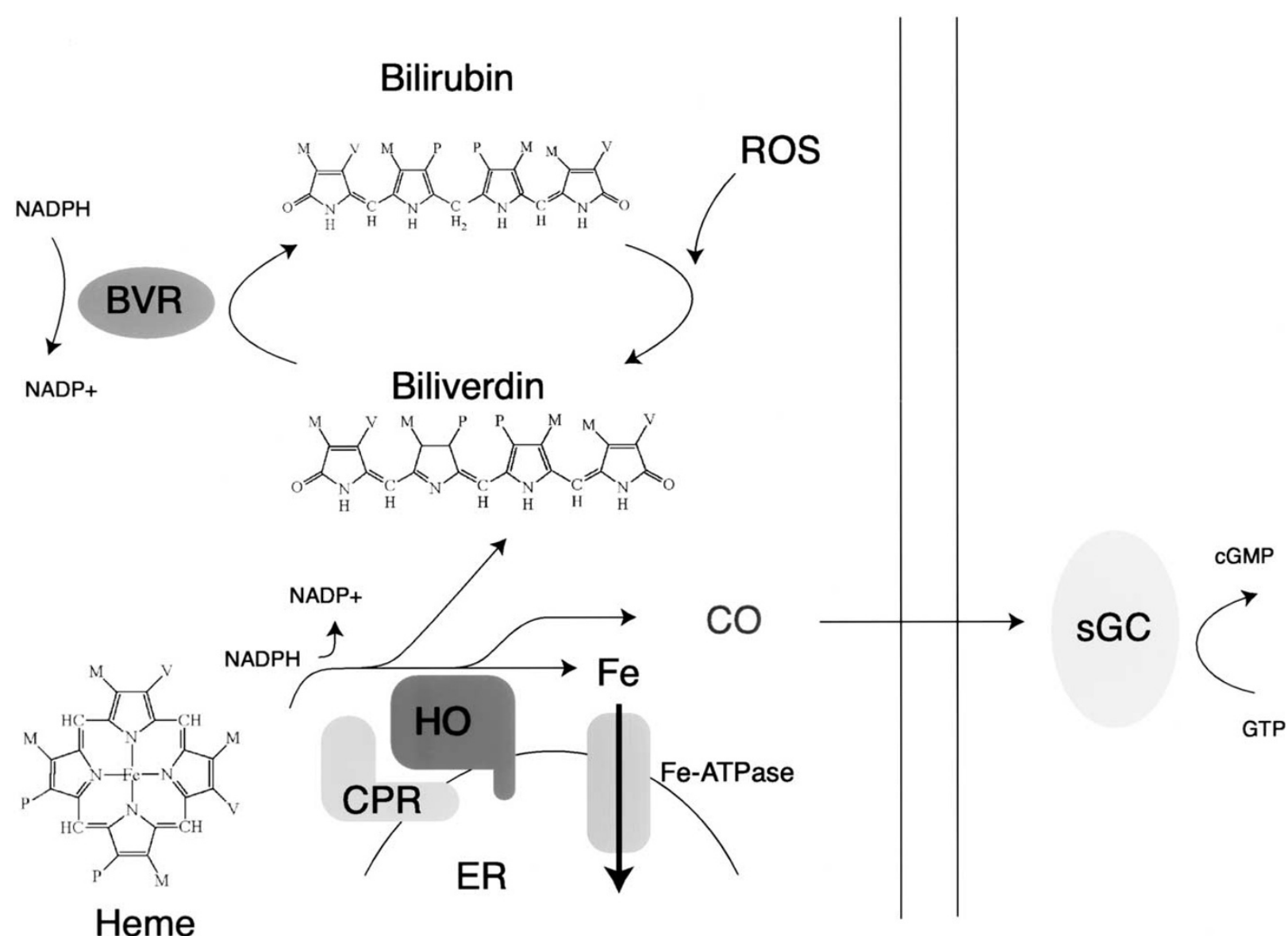

Figure 1. Heme oxgenase $(\mathrm{HO})$ degrades heme to produce three products: iron, carbon monoxide, and biliverdin. Heme is a highly conjugated porphyrin ring $(\mathrm{M}=$ methyl, $\mathrm{V}=$ vinyl, $\mathrm{P}=$ propionate $)$ that chelates an iron molecule. $\mathrm{HO}$, acting with NADPH cytochrome P450 reductase (CPR), cleaves the $\alpha$-meso bond of the heme by a mixed oxidative-reductive reaction, releasing a one-carbon fragment as carbon monoxide (CO). $\mathrm{CO}$ acts to stimulate soluble guanylyl cyclase (sGC). The free iron molecule $(\mathrm{Fe})$ is removed from the cytoplasm by an Fe-ATPase. Biliverdin is rapidly reduced to bilirubin by the soluble enzyme biliverdin reductase. Reactive oxygen species (ROS) can be scavenged by bilirubin, protecting the cell from oxidative stress. ROSs oxidize bilirubin to form biliverdin, which can be reduced to bilirubin by BVR, completing a catalytic cycle which can account for the non-stoichiometric protection of bilirubin against hydrogen peroxide toxicity.

cultures, $0.1 \mu \mathrm{M}$ PMA augments $\mathrm{HO} 2$ activity and bilirubin staining and prevents hydrogen peroxide elicited neurotoxicity (Doré et al. 1999a). By contrast, 1.0 $\mu \mathrm{M}$ PMA down-regulates protein kinase $\mathrm{C}$, fails to activate $\mathrm{HO} 2$ and is not neuroprotective (Doré et al. 1999a).

The physiologic neuroprotectant role of bilirubin in intact animals is evident from studies showing accentuation of vascular stroke damage in $\mathrm{HO}^{-/-}$mice (Doré et al. 1999b, 2000) This is not a nonspecific effect of "debility" in the $\mathrm{HO}^{-/-}$animals who appear outwardly healthy. $\mathrm{HO}^{-/-}$mice, who are far more debilitated than $\mathrm{HO}^{-1-}$ mice and die at a young age, do not manifest increased stroke damage. This specificity is further emphasized by the worsening of stroke damage elicited by the $\mathrm{HO}$ inhibitor tin protoporphyrin IX and the absence of additivity in neural damage in $\mathrm{HO}^{-/-}$mice treated with tin protoporphyrin IX (Doré et al. 1999b). The accentuated neural damage in $\mathrm{HO}^{-/-}$brain fol- lowing stroke displays a marker profile reflecting apoptotic rather than necrotic cell death, and resembles the apoptotic profile of augmented cell death in cerebellar granule cell cultures of $\mathrm{HO}_{2}{ }^{-/-}$mice (Doré et al. 2000).

Thus, bilirubin is a physiologic neuroprotectant which may lessen neural damage following various types of hypoxic insults associated not only with stroke but also with neurodegenerative disease. We have recently obtained direct evidence for a neuroprotective role of HO2 linked to Alzheimer's disease (Takahashi et al. 2000). Yeast 2-hybrid and other protein-binding studies reveal $\mathrm{HO} 2$ and $\mathrm{HO} 1$ binding to the amyloid precursor protein (APP). This interaction has no effect on APP processing but does result in inhibition of $\mathrm{HO}$ activity. The APP derivatives that occur in familial forms of Alzheimer's disease are much more potent than normal APP in inhibiting $\mathrm{HO}$ activity. To examine in vivo consequences of this finding, we utilized mice with the 
"Swedish" mutant APP. HO2 activity in cerebral cortical cultures from these mice is markedly reduced as is evident by profoundly diminished staining for bilirubin. Moreover, neurotoxicity elicited by hemin or hydrogen peroxide is markedly increased in cultures from Swedish mutant brain. While the HO inhibitor tin protoporphyrin IX worsens neurotoxicity in control cultures, it is ineffective in Swedish cultures in which NO activity is already diminished. We presume that the loss of physiologic protection by bilirubin in brains of patients with familial Alzheimer's disease increases sensitivity to the neurotoxic effects of the high levels of amyloid beta peptide generated in these patients.

\section{IRON}

Very little attention had been devoted to the third product of $\mathrm{HO}$, ferrous iron. However, a little reflection reveals that cells must have some mechanism to deal with the iron released by HO. Ferrous iron is notoriously toxic even in low concentrations. It participates in the Fenton reaction giving rise to hydroxyl free radical, one of the most toxic biological species, which accounts for a major portion of cell death in stroke and septic shock. We noted a striking gap in the literature on cellular iron dynamics. Much was known about how iron enters cells. It is bound in the plasma to transferrin, enters cells when the transferrin receptor is endocytosed and is stored in cells bound to ferritin. As with other cations such as calcium, one would expect there to exist a pump that extrudes iron from cells, but none had been described in the literature.

Our first hint of a link between $\mathrm{HO}$ and iron extrusion came from studies characterizing $\mathrm{HO}^{-/-}$mice (Poss and Tonegawa 1997). These animals die at an early age from massive iron overload in the liver and kidney. Yet, their plasma iron levels are subnormal. The iron overload in tissues was surprising, considering that $\mathrm{HO}$ is responsible for extracting iron out of the mitochondrial heme-containing proteins, so that in the absence of HO1 we might have expected less iron in cells. Presumably, in the absence of HO1 mitochondrial proteins continue to turn over but iron fails to leave cells, because $\mathrm{HO} 1$ somehow is associated with iron extrusion. A role for $\mathrm{HO} 1$ in removing iron from cells would also explain the low serum iron in $\mathrm{HO}^{-/-}$mice.

We speculated that HO1 is closely linked to cellular iron extrusion mechanisms. This would prevent iron generated by $\mathrm{HO}$ from damaging cells. To test this hypothesis, we labeled endogenous iron pools of fibroblasts with ${ }^{55} \mathrm{Fe}^{2+}$ and monitored physiologic influx and efflux of iron (Ferris et al. 1999). Transfection of HEK 293 cells with HO1 markedly accelerates efflux. By contrast, primary fibroblasts cultures from $\mathrm{HO}^{-/-}$mice manifest a markedly decreased iron efflux.
We wondered whether regulation of iron efflux by HO1 determines cellular viability in the presence of oxidative stresses. HO1 knockout fibroblasts are much more sensitive to apoptotic death elicited by serum deprivation (Ferris et al. 1999). Cell death is prevented by iron chelators but not by 8-bromo-cyclic GMP or bilirubin, indicating that iron, but not the other two products of NO, regulates viability of these cells.

Our studies of iron efflux imply the existence of a pump mediating iron extrusion, analogous to calcium ATPases. No such iron pump had been previously described, conceivably because of difficulties with ferric iron salts that readily precipitate. Utilizing ${ }^{55} \mathrm{Fe}^{2+}$ salts in potassium gluconate buffer, we successfully identified ATP-dependent iron accumulation into microsomal vesicles (Barañano et al. 2000). Binding is absolutely dependent upon ATP with the relative activity of various nucleotides paralleling known affinities for P-type ATPases. Like HO1, the iron pump is most highly concentrated in the spleen, the repository of senescent erythrocytes. Both $\mathrm{HO} 1$ and the iron pump appear localized to the endoplasmic reticulum. We were struck with the impressive inducibility of the iron pump. In macrophage cultures iron itself causes a 10-fold enhancement of pump activity. There is a doubling in the first two hours followed by a 16-hour plateau and then a quintupling within another two hours. The first phase of induction appears independent of new protein synthesis while the second phase requires transcriptional and translational activity, being blocked by actinomycin $\mathrm{D}$ and cycloheximide. Inducibility is evident in intact animals treated with glycerol that causes muscle degradation with a massive release of iron into the circulation.

What is the disposition of the iron pump in the brain? Under basal conditions HO1 levels in the brain are quite low, although high levels can be elicited following various stresses that induce $\mathrm{HO} 1$. Because $\mathrm{HO} 2$ is intimately linked to neural protection, we presume that in neurons in the brain $\mathrm{HO} 2$ would also be involved in regulating iron efflux, although there is not yet any direct evidence for this.

\section{CONCLUSIONS}

Is there any biological significance to the fact that HO produces three biologically active substances? Might they act in some coordinated fashion? In terms of the direct actions of $\mathrm{CO}$, those that we know relate to its stimulation of cyclic GMP formation leading to relaxation of intestinal smooth muscle and vasodilatation. We do not know the consequences of comparable actions in the brain. One might reason by analogy with NO, which also stimulates cyclic GMP. Synaptic NO may mediate behavioral inhibition, at least in the area of aggression and sexual activity, because nNOS knockout mice are extraordinarily aggressive and display ex- 
cess, inappropriate sexual activity (Nelson et al. 1995). Relaxation of smooth muscle certainly conserves energy which would be cytoprotective in relationship to oxidative and other stressors that kill cells by energy depletion. Cytoprotective muscle relaxation might be synergistic with the cytoprotective effects of bilirubin. The link of HO1 to iron efflux may provide another means of cytoprotection. Thus, a model emerges whereby the three products of $\mathrm{HO}$ could work in concert to preserve cellular integrity.

Are there other precedents whereby multiple products of an enzyme work in coordination, especially in the neurotransmitter arena? NOS gives rise to NO and citrulline. Thus far, there has not been any major evidence for neural actions of citrulline. Among neuropeptides, protein precursors sometimes contain multiple peptides. One of the two enkephalin precursors encodes both methionineenkephalin and leucine-enkephalin. Another precursor encodes only leucine-enkephalin. The two enkephalins tend to be stored in different neurons, although in some cases they occur in the same neurons. Whether or not they function synergistically is not altogether clear. Proopiomelanocortim (POMC) encodes ACTH and betaendorphin. While there is minimal evidence of ACTH and beta endorphin working together, there have not been extensive studies to evaluate this possibility.

\section{ACKNOWLEDGMENTS}

Supported by USPHS grants MH-18501, DA-00266, Research Scientist Award DA-00074 (SHS) and fellowship DA-05900 (DEB).

\section{REFERENCES}

Barañano DE, Wolosker H, Bae BI, Barrow RK, Snyder SH, Ferris CD (2000): A mammalian iron ATPase induced by iron. J Biol Chem 275:15,166-15,173

Bredt DS, Snyder SH (1990): Isolation of nitric oxide synthetase, a calmodulin-requiring enzyme. Proc Natl Acad Sci USA 87:682-685

Burnett AL, Lowenstein CJ, Bredt DS, Chang TS, Snyder SH (1992): Nitric oxide: a physiologic mediator of penile erection. Science 257:401-403

Burnett AL, Johns DG, Kriegsfeld LJ, Klein SL, Calvin DC, Demas GE, Schramm LP, Tonegawa S, Nelson RJ, Snyder SH, Poss KD (1998): Ejaculatory abnormalities in mice with targeted disruption of the gene for heme oxygenase- 2 . Nat Med 4:84-87

Doré S, Takahashi M, Ferris CD, Hester LD, Guastella D, Snyder SH (1999a): Bilirubin, formed by activation of heme oxygenase-2, protects neurons against oxidative stress injury. Proc Natl Acad Sci USA 96:2445-2450

Doré S, Sampei K, Goto S, Alkayed NJ, Guastella D, Blackshaw S, Gallagher M, Traystman RJ, Hurn PD, Koehler $\mathrm{RC}$, Snyder SH (1999b): Heme oxygenase-2 is neuroprotective in cerebral ischemia. Mol Med 5:656-663

Doré S, Goto S, Sampei K, Blackshaw S, Hester LD, Ingi T, Sawa A, Traystman RJ, Koehler RC, Snyder SH (2000):
Heme oxygenase-2 acts to prevent neuronal death in brain cultures and following transient cerebral ischemia. Neuroscience 99:587-592

Ferris CD, Jaffrey SR, Sawa A, Takahashi M, Brady SD, Barrow RK, Tysoe SA, Wolosker H, Baranano DE, Dore S, Poss KD, Snyder SH (1999): Heme oxygenase-1 prevents cell death by regulating cellular iron. Nature Cell Biol 1:152-157

Friebe A, Schultz G, Koesling D (1996): Sensitizing soluble guanylyl cyclase to become a highly $\mathrm{CO}$-sensitive enzyme. Embo J 15:6863-6868

Ingi T, Ronnett GV (1995): Direct demonstration of a physiological role for carbon monoxide in olfactory receptor neurons. J Neurosci 15:8214-8222

Ingi T, Chiang G, Ronnett GV (1996): The regulation of heme turnover and carbon monoxide biosynthesis in cultured primary rat olfactory receptor neurons. J Neurosci 16:5621-5628

Maines MD, Trakshel GM, Kutty RK (1986): Characterization of two constitutive forms of rat liver microsomal heme oxygenase. Only one molecular species of the enzyme is inducible. J Biol Chem 261:411-419

Nelson RJ, Demas GE, Huang PL, Fishman MC, Dawson VL, Dawson TM, Snyder SH (1995): Behavioural abnormalities in male mice lacking neuronal nitric oxide synthase. Nature 378:383-386

Poss KD, Tonegawa S (1997): Heme oxygenase 1 is required for mammalian iron reutilization. Proc Natl Acad Sci USA 94:10,919-10,924

Stocker R, Yamamoto Y, McDonagh AF, Glazer AN, Ames BN (1987a): Bilirubin is an antioxidant of possible physiological importance. Science 235:1043-1046

Stocker R, Glazer AN, Ames BN (1987b): Antioxidant activity of albumin-bound bilirubin. Proc Natl Acad Sci USA 84:5918-5922

Takahashi M, Dore S, Ferris CD, Tomita T, Sawa A, Wolosker $\mathrm{H}$, Borchelt DR, Iwatsubo T, Kim SH, Thinakaran G, Sisodia SS, Snyder SH (2000): Amyloid precursor proteins inhibit heme oxygenase activity and augment neurotoxicity in Alzheimer's disease. Neuron 28:461-473

Trakshel GM, Kutty RK, Maines MD (1986): Purification and characterization of the major constitutive form of testicular heme oxygenase. The noninducible isoform. J Biol Chem 261:11,131-11,137

Verma A, Hirsch DJ, Glatt CE, Ronnett GV, Snyder SH (1993): Carbon monoxide: a putative neural messenger. Science 259:381-384

Wolosker H, Blackshaw S, Snyder SH (1999): Serine racemase: a glial enzyme synthesizing D-serine to regulate glutamate-N-methyl-D-aspartate neurotransmission. Proc Natl Acad Sci USA 96:13,409-13,414

Wolosker H, D'Aniello A, Snyder SH (2000): D-Aspartate disposition in neuronal and endocrine tissues: ontogeny, biosynthesis and release. Neuroscience 100:183-189

Zakhary R, Gaine SP, Dinerman JL, Ruat M, Flavahan NA, Snyder SH (1996): Heme oxygenase 2: endothelial and neuronal localization and role in endothelium-dependent relaxation. Proc Natl Acad Sci USA 93:795-798

Zakhary R, Poss KD, Jaffrey SR, Ferris CD, Tonegawa S, Snyder SH (1997): Targeted gene deletion of heme oxygenase 2 reveals neural role for carbon monoxide. Proc Natl Acad Sci USA 94:14,848-14,853 